\title{
A Comparative Study of Controllers for CSI Fed Induction Motor
}

\author{
Piush Kumar* and Vineeta Agarwal ${ }^{\dagger}$ \\ ${ }^{\dagger *}$ Electrical Engineering Department, M.N.N.I.T., Allahabad, India
}

\begin{abstract}
This paper presents a comparative study of P and PI controllers for a current source inverter (CSI) fed induction motor drive system. A dq model has been used which incorporates the induction motor and the inverter power supply with current feedback. The model is used first to generate the steady state curves to determine the operating point through computer simulations using the software package MATLAB. Then a transient analysis has been carried out for different values of the speed and current controller parameters. The controller value is adjusted by the Ziegler-Nichols method. It has been observed that the transient time to reach the steady state value is larger with the PI controller than with the P controller.
\end{abstract}

Key Words: Current Source Inverter, Induction Motor Drives, Ziegler Nichols Methods

\section{INTRODUCTION}

Due to the inherent disadvantages in voltage source inverters [1], a slip regulated [2] current source inverter (CSI) has been preferred for wide range speed control [3] of induction motors. Current source inverter fed drives find application in high power drives such as fan drives, where fast dynamic response is not needed [4], because of the following advantages:

- Inherent four quadrant operation: CSI drives employ fully controlled silicon-controlled rectifier (SCR) converters at the input. Under regeneration the polarity of the voltage at the converter terminals will reverse and the energy will be fed back to the utility. Therefore, regeneration is built into the system and unlike VSI fed drives it does not require an additional circuit.

- Reliability: the dc link reactor will limit the rate of rise in current during a short circuit. As a result, the drives can be easily protected during short circuits. This results in improved reliability for the drive [5].

The most common choice for a controller is a PID compensator since it has a simple structure and it can offer satisfactory performance over a wide range of operations. However, in drive applications, the derivative part of the controller is not used and so simple PI controllers are being used instead.

A lot of strategies have been proposed to tune PI controllers [6]. The frequency response method has been used in [7] to design and tune PI controller gains based on the specified phase and gain margins as well as the cross over frequency. Furthermore, root locus and pole assignment design techniques

Manuscript received Jan. 29, 2009; revised Jan. 1, 2010

$\dagger$ Corresponding Author: vineeta_agarwal123@ rediffmail.com

Tel: +915-3222-71707, M.N.N.I.T.

* Dept. of Electrical and Electronics Engg., M.N.N.I.T., India have been proposed in addition to transient response specifications. All these methods are considered as model based strategies and the efficiency of the tuning law depends on the accuracy of the proposed models as well as the assumed conditions with respect to the actual operating conditions. The most famous, which is frequently used in industrial applications is the Ziegler-Nichols method which does not require a system model and its control parameters are designed from the plant step response. Tuning using this method is characterized by good disturbance rejection. This paper presents the dynamic analysis of a self commutated current source inverter (SCCSI) fed induction motor system, using dq equations. The values of the speed and current controller parameters are adjusted by the Ziegler-Nichols method. The steady state characteristics are also investigated by incorporating a proportional and integral controller in speed and current loops at various motor speeds.

\section{CSI FED IM DRIVE SYSTEM}

Current controlled induction motor drives, in general are made up of a three phase power source, a controlled rectifier bridge, a DC link smoothening reactor, a current source inverter and a three phase squirrel cage induction motor as shown in Fig. 1.

The magnitude and polarity of the speed error are used to determine the slip speed reference. This maintains the air gap flux in the machine at a constant value. It is also used to determine the DC link current reference value. Rectifier output voltage is controlled by a PI controller working on the DC link current error that decides the input current of the CSI. The slip speed is added to the rotor speed in order to determine the synchronous speed, which then determines the inverter operating frequency. 


$$
\left[\begin{array}{c}
\cdot \\
i_{d s} \\
\cdot \\
i_{q s} \\
\cdot \\
i_{d r} \\
\cdot \\
i_{q r}
\end{array}\right]=\frac{1}{l_{1}}\left[\begin{array}{cccc}
-r_{s} l_{r} & \omega_{e} l_{1}+\omega_{r} l_{m}^{2} & r_{r} l_{m} & \omega_{r} l_{m} l_{r} \\
-\left(\omega_{e} l_{1}+\omega_{r} l_{m}^{2}\right) & -r_{s} l_{r} & \omega_{r} l_{m} l_{r} & r_{r} l_{m} \\
r_{s} l_{m} & -\omega_{r} l_{m} l_{s} & -r_{r} l_{s} & \omega_{e} l_{1}-\omega_{r} l_{s} l_{r} \\
\omega_{r} l_{s} l_{m} & r_{s} l_{m} & -\left(\omega_{e} l_{1}-\omega_{r} l_{s} l_{r}\right) & -r_{r} l_{s}
\end{array}\right]\left[\begin{array}{c}
i_{d s} \\
i_{q s} \\
i_{d r} \\
i_{q r}
\end{array}\right]+\frac{1}{l_{1}}\left[\begin{array}{ccc}
L_{r} & 0 & 0 \\
0 & L_{r} & 00 \\
-l_{m} & 0 & 00 \\
0 & -l_{m} 00
\end{array}\right]\left[\begin{array}{c}
v_{d s} \\
v_{q s} \\
0 \\
0
\end{array}\right] .
$$

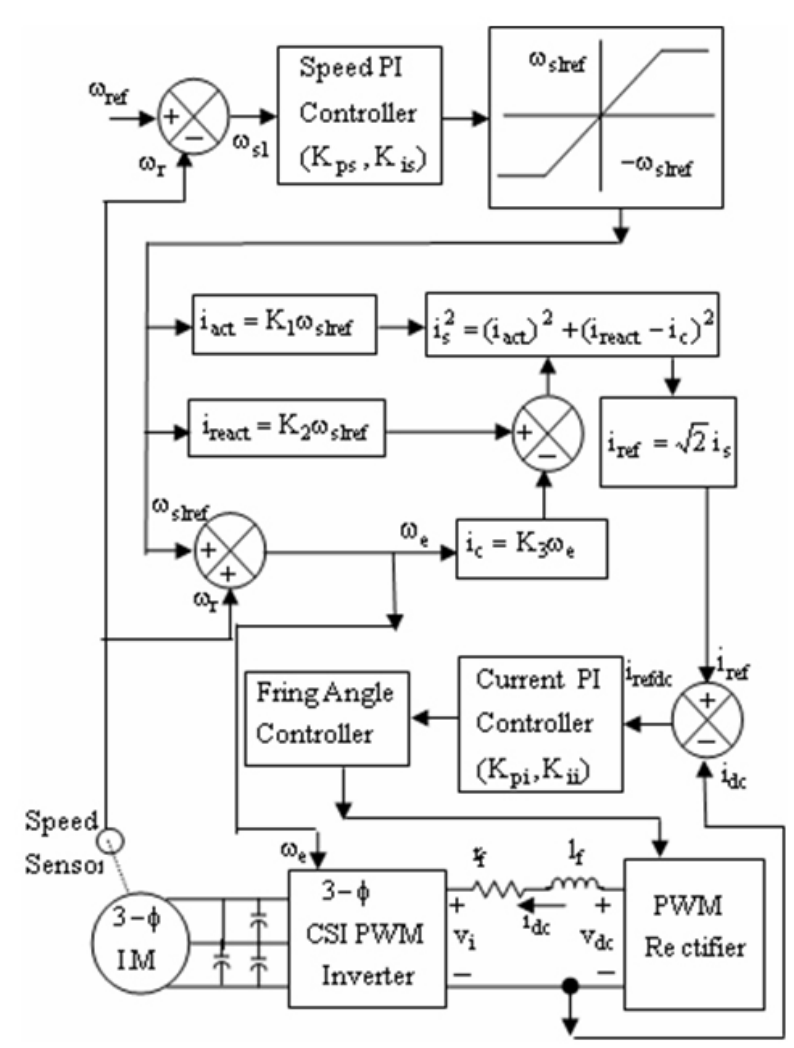

Fig. 1. Closed Loop Control of IM fed by CSI.

\section{Modeling OF A CSI FED IM DRIVE SYSTEM}

The modeling of a CSI fed induction motor system has been done in different structures and cascaded together to obtain the overall performance of the system.

\section{A. Modeling of Induction Motor}

The voltages and currents of the squirrel cage induction motor can be represented in a synchronously rotating $d-q$ reference frame as in (1).

$$
\left[\begin{array}{c}
v_{q s} \\
v_{d s} \\
v_{q r} \\
v_{d r}
\end{array}\right]=\left[\begin{array}{cccc}
r_{s}+p l_{s} & \omega_{e} l_{s} & p l_{m} & \omega_{e} l_{m} \\
-\omega_{e} l_{s} & r_{s}+p l_{s}-\omega_{e} l_{m} & p l_{m} \\
p l_{m} & \omega_{s l} l_{m} & r_{r}+p l_{r} & \omega_{s l} l_{r} \\
-\omega_{s l} l_{m} & p l_{m} & -\omega_{s l} l_{r} & r_{r}+p l_{r}
\end{array}\right]\left[\begin{array}{c}
i_{q s} \\
i_{d s} \\
i_{q r} \\
i_{d r}
\end{array}\right]
$$

By solving (1), the following model of an induction motor is obtained:

$$
\text { Where } l_{1}=l_{s} l_{r}-l_{m}^{2} \text {. }
$$

The machine and load torque are related as:

$$
p J \omega_{r}=T_{e}-T_{1} .
$$

In the above equation, friction and windage losses are neglected. The electromagnetic torque, $T_{e}$ and the load torque, $T_{1}$ are given by the following equations:

$$
\begin{aligned}
& T_{e}=\frac{3 P}{4} l_{m}\left(i_{q s} i_{d r}-i_{d s} i_{q r}\right) \\
& T_{l}=T_{L}\left(\frac{\omega_{r}}{\omega_{b}}\right) .
\end{aligned}
$$

The load torque in the present case is considered to vary linearly with the speed.

\section{B. Modeling of Capacitors}

For the balanced condition, the equations related to the output capacitors can be expressed, in term of phase voltages as follows:

$$
\begin{aligned}
& i_{a}=3 C \frac{d v_{a s}}{d t}+i_{a s} \\
& i_{b}=3 C \frac{d v_{b s}}{d t}+i_{b s} \\
& i_{c}=3 C \frac{d v_{c s}}{d t}+i_{c s} .
\end{aligned}
$$

By transforming the inverter output currents $i_{a}, i_{b} \& i_{c}$ in a synchronously rotating $\mathrm{d}-\mathrm{q}$ reference frame, the following equations are obtained:

$$
\begin{aligned}
& i_{q}=3 C \frac{d v_{q s}}{d t}+3 C \omega_{e} v_{d s}+i_{q s} \\
& i_{d}=3 C \frac{d v_{d s}}{d t}+3 C \omega_{e} v_{q s}+i_{d s} .
\end{aligned}
$$

In a CSI, the inverter output current flow for $120^{\circ}$ of each half cycle is in the form of a rectangular wave. Their harmonic components are neglected on the assumption that the drive system stability is primarily determined by the fundamental component of each variable. Thus, the inverter output currents considering only the fundamental components are achieved as below: 


$$
\left[\begin{array}{c}
0 \\
0 \\
0 \\
0 \\
\frac{-2 \sqrt{3}}{3 \pi C} i_{d c} \\
0
\end{array}\right]=\left[\begin{array}{cccccc}
-l_{r} r_{s} & -\left(\omega_{e} l_{1}+\omega_{r} l_{m}^{2}\right) & r_{r} l_{m} & -\omega_{r} l_{r} l_{m} & l_{r} & 0 \\
\omega_{e} l_{1}+\omega_{r} l_{m}^{2} & -r_{s} l_{r} & \omega_{r} l_{m} l_{r} & r_{r} l_{m} & 0 & l_{r} \\
l_{m} r_{s} & \omega_{r} l_{m} l_{s} & -l_{s} r_{r} & \omega_{r} l_{s} l_{r}-\omega_{e} l_{1} & -l_{m} & 0 \\
-\omega_{r} l_{s} l_{m} & r_{s} l_{m} & \omega_{e} l_{1}-\omega_{r} l_{r} l_{s} & -l_{s} r_{r} & 0 & -l_{m} \\
\frac{-l_{1}}{3 C} & 0 & 0 & 0 & 0 & -l_{1} \omega_{e} \\
0 & \frac{-l_{1}}{3 C} & 0 & 0 & l_{1} \omega_{e} & 0
\end{array}\right]\left[\begin{array}{c}
i_{q s o} \\
i_{d s o} \\
i_{q r o} \\
i_{d r o} \\
v_{q s o} \\
v_{d s o}
\end{array}\right] .
$$

$$
i_{q}=\frac{2 \sqrt{3}}{\pi} i_{d c}, i_{d}=0
$$

From equations (10) to (12) we obtain:

$$
\begin{aligned}
& p v_{d s}=\frac{1}{3 C}\left(-i_{d s}+3 C \omega_{e} v_{q s}\right) \\
& p v_{q s}=\frac{1}{3 C}\left(\frac{2 \sqrt{3}}{\pi} i_{d c}-3 C \omega_{e} v_{d s}-i_{q s}\right) .
\end{aligned}
$$

\section{Modeling of the DC link}

The DC link is expressed as:

$$
l_{f} p i_{d c}+r_{f} i_{d c}=v_{d c}-v_{i} .
$$

If the inverter is assumed to be lossless, the inverter input voltage is:

$$
v_{i}=\frac{3 \sqrt{3}}{\pi} v_{q s} .
$$

The relationship between the stator rms current and the $\mathrm{dc}$ reference current is:

$$
i_{\text {ref }}=\sqrt{2} i_{s}
$$

\section{Steady State Characteristics}

The steady state equation of a CSI fed induction motor is given by (18) where the DC link current $i_{d c}$, is taken as an input parameter:

where the subscript ' $\mathrm{o}$ ' denotes the steady state value. The parameter values of the induction motor and DC link used in this paper are as 3 -phase $400 / 440 \mathrm{~V}, 50 \mathrm{~Hz}, 4$ poles, 7 amps, $r_{s}=r_{r}=5.53 \Omega / p h, l_{s}=l_{r}=0.68 H, l_{m}=0.6503 H, l_{f}=$ $0.05 H, r_{f}=3 \Omega$ and $C=28.22 \mu F, K_{1}=0.0821 \& K_{2}=$ 0.2474 .

Once the DC link current required for an arbitrary speed and load torque is determined, all the motor currents and the developed electromagnetic torque can be obtained using equations 18 and 5 respectively. Fig. 2 shows the torque versus the slip characteristics. Near the synchronous speed i.e. at low slips the torque is linear and is proportional to the slip. Beyond the maximum torque the torque is approximately inversely proportional to the slip. Fig. 3 shows the rotor current characteristic for different value of the dc link current. It shows that at unity slip the current taken by the motor is large, as expected.

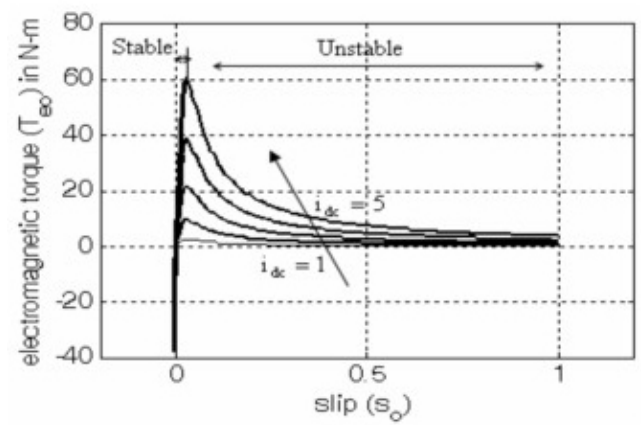

Fig. 2. Plot of electromagnetic torque (Te) vs slip(s).

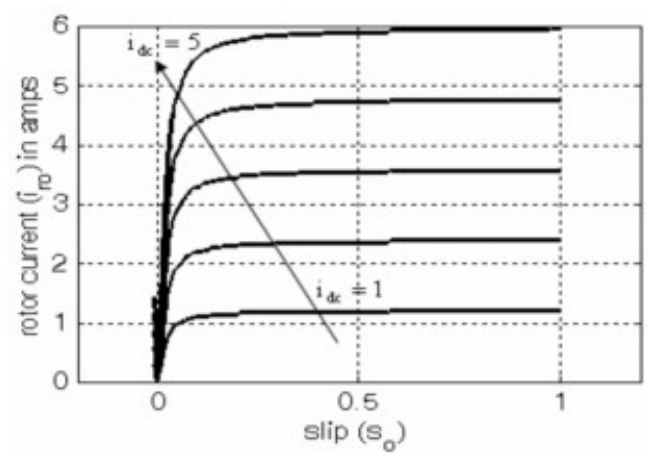

Fig. 3. Plot of rotor current (ir) vs slip(s).

\section{DYNAMIC CHARACTERISTICS}

To investigate the dynamic characteristics, the equations $1,4,5,10,11,15$ and 16 are linearzed about a steady state operating point. Then the resulting state equation can be expressed as:

$$
\dot{x}=A x+B u .
$$

where:

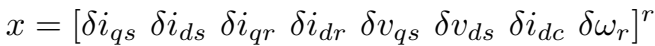

$$
\begin{aligned}
& u=\left[\begin{array}{lll}
\delta \omega_{e} & \delta v_{d c} & \delta T_{l}
\end{array}\right]^{T} \text {. } \\
& B=\frac{1}{l_{1}}\left[\begin{array}{ccc}
-l_{1} i_{d s o} & 0 & 0 \\
l_{1} i_{q s o} & 0 & 0 \\
-l_{1} i_{d r o} & 0 & 0 \\
l_{1} i_{q r o} & 0 & 0 \\
-l_{1} v_{d s o} & 0 & 0 \\
l_{1} v_{q s o} & 0 & 0 \\
0 & \frac{l_{1}}{l_{f}} & \\
0 & 0 & -\frac{P}{2 J}
\end{array}\right] .
\end{aligned}
$$


$A=\frac{1}{1_{1}}\left[\begin{array}{cccccccc}-r_{s} l_{r} & l_{m}^{2} \omega_{s l o}-l_{s} l_{r} \omega_{e o} & r_{r} l_{m} & -\omega_{r o} l_{m} l_{r} & l_{r} & 0 & 0 & -\left(l_{m}^{2} i_{d s o}+l_{m} l_{r} i_{d r o}\right) \\ l_{r} l_{s} \omega_{e o}-l_{m}^{2} \omega_{s l o} & -l_{r} l_{s} & l_{r} l_{m} \omega_{r o} & l_{m} l_{r} & 0 & l_{r} & 0 & \left(l_{m}^{2} i_{q s o}+l_{m} l_{r} i_{q r o}\right) \\ r_{s} l_{m} & l_{s} l_{m} \omega_{r o} & -r_{r} l_{s} & l_{m}^{2} \omega_{e o}-l_{s} l_{r} \omega_{s l o}-l_{m} & 0 & 0 & \left(l_{m} i_{d s o}+l_{r} i_{d r o}\right) l_{s} \\ -l_{s} l_{m} \omega_{r o} & l_{m} r_{s} & -\left(l_{m}^{2} \omega_{e o}-l_{r} l_{s} \omega_{s l o}\right) & -r_{r} l_{s} & 0 & -l_{m} & 0 & -\left(l_{m} i_{q s o}+l_{r} i_{q r o}\right) l_{s} \\ -\frac{l_{1}}{3 C} & 0 & 0 & 0 & 0 & -l_{1} \omega_{e o} \frac{2 l_{1}}{\pi C \sqrt{3}} & 0 \\ 0 & -\frac{l_{1}}{3 C} & 0 & 0 & l_{1} \omega_{e o} & 0 & 0 & 0 \\ 0 & 0 & 0 & 0 & \frac{3 \sqrt{3} l_{1}}{\pi l_{f}} & 0 & -\frac{r_{f} l_{1}}{l_{f}} & 0 \\ \frac{3 P^{2} l_{m} l_{1}}{8 J} i_{d r o} & -\frac{3 P^{2} l_{m} l_{1}}{8 J} i_{q r o} & -\frac{3 P^{2} l_{m} l_{1}}{8 J} i_{d s o} & \frac{3 P^{2} l_{m} l_{1}}{8 J} i_{q s o} & 0 & 0 & 0 & 0\end{array}\right] .(23)$

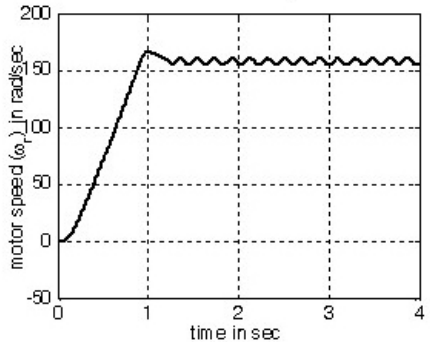

Fig. 4. Plot of rotor speed $\left(\omega_{r}\right)$ vs time (t) when $\omega_{r}=150 \mathrm{rad} / \mathrm{sec} \&$ $T_{l}=0.8 N-m$.

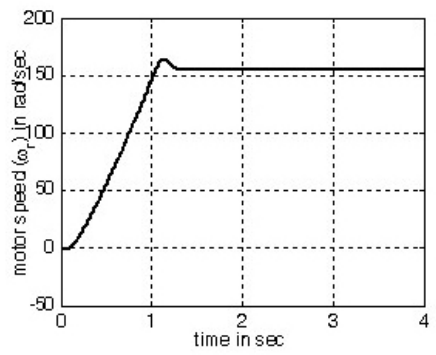

Fig. 5. Plot of rotor speed $\left(\omega_{r}\right)$ vs time (t) with $\mathrm{P}$ controller when $\omega_{r}=$ $150 \mathrm{rad} / \mathrm{sec} \& T_{l}=0.8 N-m$.

Now equation (19) is solved with the help of MATLAB for investigating the starting transients of the drive. Keeping the load torque at a very low value $(0.8 \mathrm{~N}-\mathrm{M})$ and with the help of the steady state characteristic shown in Fig. 2 the DC link current range is observed for a corresponding load torque to obtain the steady state operating value. The positive slope region of the torque slip characteristic provides stable operation. By adjusting the controller gain so that the speed is $\omega_{r}=150 \mathrm{rad} / \mathrm{sec}$ the sustain oscillation can be obtained at gain values of $K_{\text {psmax }}=60$ and $K_{\text {pimax }}=25$ and an ultimate period of $P_{u}=0.2 \mathrm{sec}$ as shown in Fig. 4 .

Now adjusting the controller gain with the Ziegler-Nichols method for the P controller with $K_{p s}=30$ and $K_{p i}=12.5$ the response obtained is shown in Fig.5. It is clear from Fig. 5 that the time to reach the steady state value is approximately $1.2 \mathrm{sec}$.

For a PI controller with $K_{p s}=27$ and $K_{p i}=11.25$ the response is shown in Fig. 6 where the time to reach the steady state value is approximately $1.3 \mathrm{sec}$. With the $\mathrm{P}$ controller there is no offset thus with a PI controller the system become sluggish as desired.

Now with an increase in the load torque to $4 \mathrm{~N}-\mathrm{M}$, the same

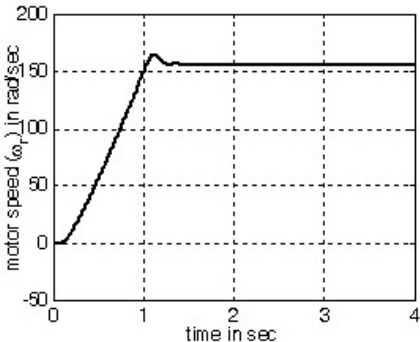

Fig. 6. Plot of rotor speed $\left(\omega_{r}\right)$ vs time $(\mathrm{t})$ with PI controller when $\omega_{r}=$ $150 \mathrm{rad} / \mathrm{sec} \& T_{l}=0.8 N-m$.

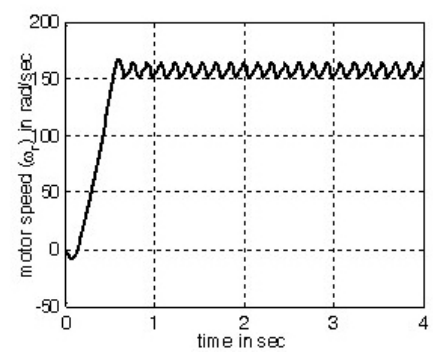

Fig. 7. Plot of rotor speed $\left(\omega_{r}\right)$ vs time (t) when $\omega_{r}=150 \mathrm{rad} / \mathrm{sec} \&$ $T_{l}=4 N-m$.

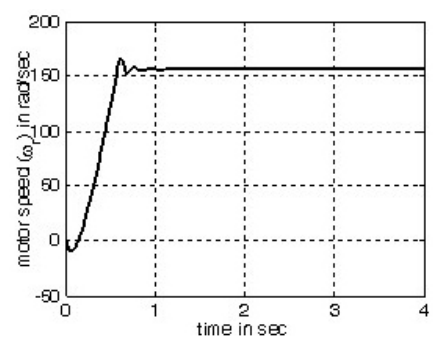

Fig. 8. Plot of rotor speed $\left(\omega_{r}\right)$ vs time $(\mathrm{t})$ with $\mathrm{P}$ controller when $\omega_{r}=$ $150 \mathrm{rad} / \mathrm{sec} \& T_{l}=4 N-m$.

controller gain value works satisfactorily as shown in Fig. 7, Fig 8 and Fig. 9 for sustain oscillation, the $\mathrm{P}$ controller and the PI controller respectively. As we increase the load torque the DC current range will increase for a corresponding load torque to obtain the steady state operating value, resulting in the speed adjusting quickly as shown in Fig. 8 and Fig 9. At the same time the DC link current will increase as shown in Fig. 16 and 18.

With a speed of $\omega_{r}=140 \mathrm{rad} / \mathrm{sec}$ and $T_{l}=0.8 N-M$ the sustain oscillation can be obtained at the gain values of $K_{\text {psmax }}=32$ and $K_{\text {pimax }}=18$ and an ultimate period of 


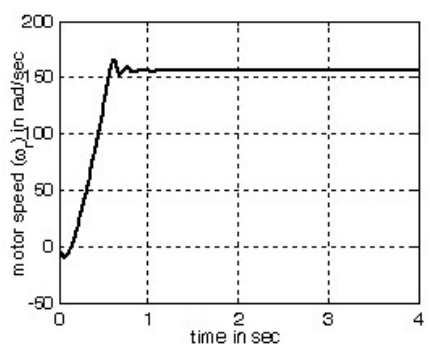

Fig. 9. Plot of rotor speed $\left(\omega_{r}\right)$ vs time (t) with PI controller when $\omega_{r}=$ $150 \mathrm{rad} / \mathrm{sec} \& T_{l}=4 N-m$.

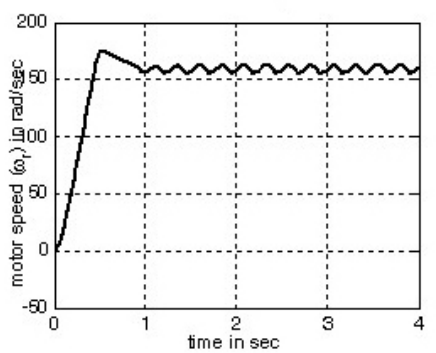

Fig. 10. Plot of rotor speed $\left(\omega_{r}\right)$ vs time (t) when $\omega_{r}=140 \mathrm{rad} / \mathrm{sec} \&$ $T_{l}=0.8 N-m$.

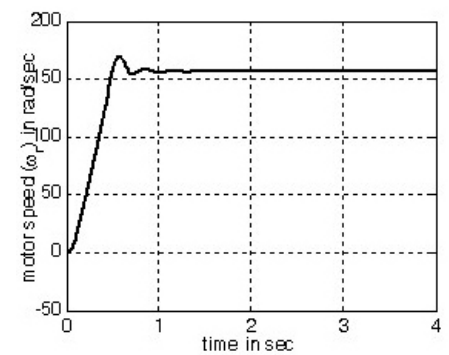

Fig. 11. Plot of rotor speed $\left(\omega_{r}\right)$ vs time (t) with P controller when $\omega_{r}=$ $140 \mathrm{rad} / \mathrm{sec} \& T_{l}=0.8 N-m$.

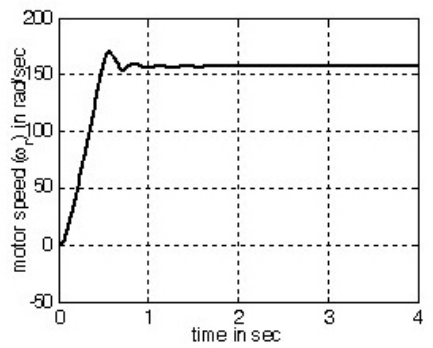

Fig. 12. Plot of rotor speed $\left(\omega_{r}\right)$ vs time (t) with PI controller when $\omega_{r}=$ $140 \mathrm{rad} / \mathrm{sec} \& T_{l}=0.8 N-m$.

$P_{u}=0.25 \mathrm{sec}$ as shown in Fig. 10. The speed transients for the $\mathrm{P}$ controller and the PI controller are as shown in Fig. 11 and Fig. 12 respectively.

It is also clear from Fig. 11 and Fig. 12 that due to the absence of an offset the PI controller gives a sluggish response as desired.

With a speed of $\omega_{r}=140 \mathrm{rad} / \mathrm{sec}$ and $T_{l}=4 N-M$ the sustain oscillation can be obtained at the gain values of $K_{\text {psmax }}=60$ and $K_{\text {pimax }}=15$ and an ultimate period of $P_{u}=0.22 \mathrm{sec}$ as shown in Fig. 13. The speed transients for the P controller and the PI controller are as shown in Fig. 14

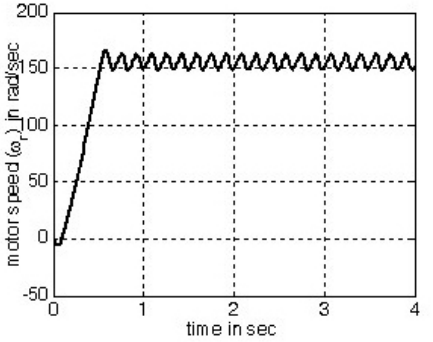

Fig. 13. Plot of rotor speed $\left(\omega_{r}\right)$ vs time (t) when $\omega_{r}=140 \mathrm{rad} / \mathrm{sec} \&$ $T_{l}=4 N-m$.

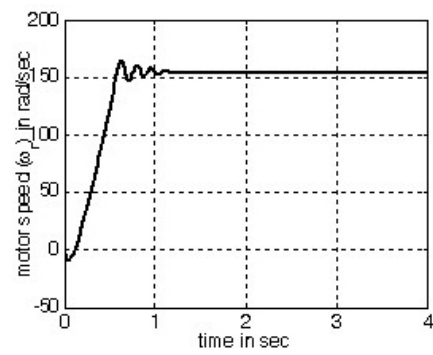

Fig. 14. Plot of rotor speed $\left(\omega_{r}\right)$ vs time (t) with $\mathrm{P}$ controller when $\omega_{r}=$ $140 \mathrm{rad} / \mathrm{sec} \& T_{l}=4 N-m$.

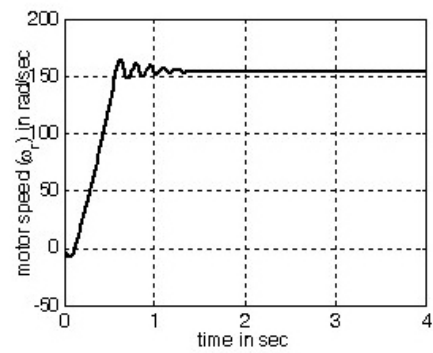

Fig. 15. Plot of rotor speed $\left(\omega_{r}\right)$ vs time (t) with PI controller when $\omega_{r}=$ $140 \mathrm{rad} / \mathrm{sec} \& T_{l}=4 N-m$.

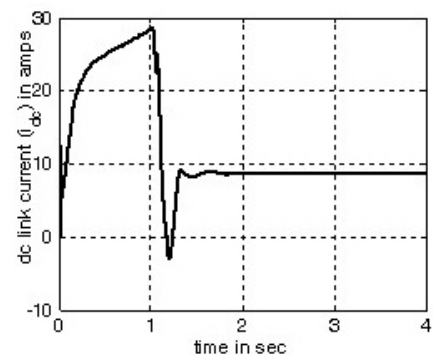

Fig. 16. Plot of dc link current $\left(i_{d c}\right)$ vs time (t) with P controller when $\omega_{r}$ $=150 \mathrm{rad} / \mathrm{sec} \& T_{l}=0.8 N-m$.

and Fig. 15 respectively.

It is clear from the above discussion that, due to the absence of an offset the system becomes sluggish with a PI controller when compared to a $\mathrm{P}$ controller. The dc link current taken by the CSI inverter with a speed of $\omega_{r}=140 \mathrm{rad} / \mathrm{sec} \&$ $T_{l}=0.8 N-m$ is approximately 9 amps as shown in Fig. 16 . However, with an increasing speed error with the same load torque the dc link current will be approximately 3.5 amps less as shown in Fig. 17.

For a large load torque the DC link current required will be large as shown in Fig. 18 and Fig. 19 for speeds of 150 


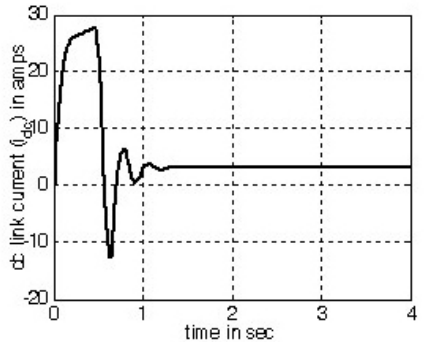

Fig. 17. Plot of dc link current $\left(i_{d c}\right)$ vs time (t) with P controller when $\omega_{r}$ $=140 \mathrm{rad} / \mathrm{sec} \& T_{l}=0.8 N-m$.

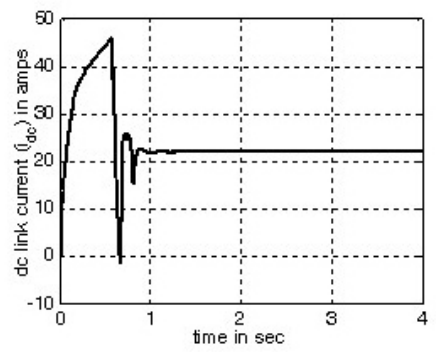

Fig. 18. Plot of dc link current $\left(i_{d c}\right)$ vs time (t) with $\mathrm{P}$ controller when $\omega_{r}$ $=150 \mathrm{rad} / \mathrm{sec} \& T_{l}=4 N-m$.

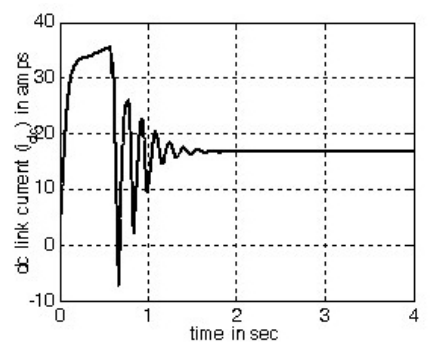

Fig. 19. Plot of dc link current $\left(i_{d c}\right)$ vs time (t) with P controller when $\omega_{r}$ $=140 \mathrm{rad} / \mathrm{sec} \& T_{l}=4 N-m$.

$\mathrm{rad} / \mathrm{sec}$ and $140 \mathrm{rad} / \mathrm{sec}$ respectively with a load torque of 4 $\mathrm{N}-\mathrm{m}$.

\section{CONCLUSiOnS}

The mathematical modeling of an induction motor drive system using a current source inverter (CSI) has been done in a synchronously rotating $\mathrm{d}-\mathrm{q}$ reference frame using proportional and integral regulators in speed and current loops. A capacitor bank is mounted on the terminal of the drive to maintain a better power factor for each operating condition of the drive. The steady-state parameters and slip regulator characteristics of the drive are determined experimentally. Steady state and transient performance are obtained by developing a computer simulation in MATLAB. A number of observations have been made to analyze the various waveforms. The motor has been loaded with a rated load. The optimum value of controller parameters is determined by the Ziegler-Nichols method for different motor speeds. It has been found that due to its very small offset the P controller works satisfactorily.

\section{REFERENCES}

[1] T. A Lipo, "Recent progress in the development of solid state ac motor drives," IEEE Trans. on Power Electronics, Vol. 3, No. 2, pp. 105-117, Apr., 1988.

[2] M. Hombu, S. Ueda and A. Ueda, "A current source GTO Inverter with sinusoidal inputs and outputs," IEEE Trans. on Ind. Application, Vol. IA-23, No. 2, pp. 247-255, Mar./Apr. 1987.

[3] B.K. Bose, "Adjustable speed ac drives-A technology status review," in Proc. of IEEE, Vol. 70, No. 2, pp. 116-135, Feb., 1982.

[4] Ajit K Chattpadhyay, "Current source inverter fed induction motor drive a state of the art research review," in JIE, Vol. 37, pp-34-46, 1991.

[5] S. Nonaka \& Y. Neba, "New GTO current source Inverter with pulse width modulation control Technique," IEEE Trans. Industrial Application, Vol. IA-22, pp. 666-672, Jul./Aug., 1986.

[6] M. K. Sang, Y. H. Woo, G. L Chang., "Improved self-tuning fuzzy PID controller for speed control of induction motor," IEEJ Trans. IA, Vol.124, No.7, 2004.

[7] M. Nasir Uddin, Hao Wen, "Development of a self-tuned neuro-fuzzy controller for induction motor drives," Industry Application Conference, $39^{\text {th }}$ IAS Annual Meeting Conference Record of the 2004, IEEE, Vol. 4, pp. 2630-2636, Oct. 2004.

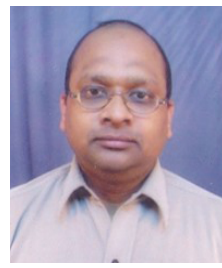

Piush Kumar graduated from Karnataka University, Dharwad, India, with a degree in Electrical and Electronics Engineering in 1998 and received his Master's degree in 2003, from Madan Mohan Malaviya Engineering College, Gorakhpur, India. He is currently pursuing a $\mathrm{PhD}$ from the Motilal Nehru National Institute of Technology, Allahabad, India. His research interests are in $\mathrm{AC}$ and $\mathrm{DC}$ drives. He has a number of publications in journals and conferences in his field. He has attended and presented papers at national conferences.

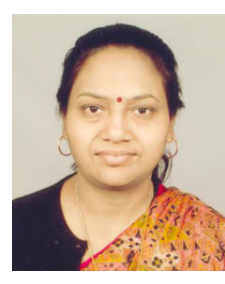

Vineeta Agarwal graduated from Allahabad University, Allahabad, India, in 1980, and received her Master's degree in 1984, from the same university. She joined the Electrical Engineering Department at the Motilal Nehru Regional Engineering College, Allahabad, India as lecturer in 1982. While teaching there, she obtained her Ph.D. in Power Electronics. At present she is a Professor in the Department of Electrical Engineering at the Motilal Nehru National Institute of Technology, Allahabad, India. She has taught numerous courses in Electrical Engineering and Electronics. Her research interests are in single phase to three-phase conversion and $\mathrm{AC}$ drives. She has a number of publications in journals and conferences in her field. She has attended and presented papers at both national and international conferences. 